CHAPTER TEN

\title{
A Lacanian approach to clinical diagnosis and addiction
}

Rik Loose

$\prod$ owards the end of his Cirilization and its Discontents Freud poses a question which he feels he cannot evade. After

1 contemplating the similarities between the development of civilization and the individual he wonders whether it is possible to make the diagnosis that "under the influence of cultural urges, some civilizations, or some epochs of civilization-possibly the whole of mankind-have become neurotic?" (Freud, 1930:144). He immediately points out the danger implicit in making this kind of diagnosis by saying that "we are only dealing with analogies and that it is dangerous, not only with men but also with concepts, to tear them from the sphere in which they have originated and been evolved" (Freud, 1930:144). This is a very important remark. 
to both the area explored and the area from which the concepts have been borrowed. When concepts and theories are transported from one area of study to another, they sometimes undergo radical changes depending on the object of study and the context they have been taken from. This process can lead to confusion and the criticism that this new application is based on a misunderstanding of their original meaning and application. This form of criticism is grounded on a particular conception of science which suggests that concepts refer to a particular reality or to particular objects in a straightforward and unproblematic way: concepts belong specifically to the objects or reality studied and should not be detached from them and deployed elsewhere. The foundation for this conception of science is a belief that nature contains laws and an order which exist independently of the researcher. Lacan calls the laws and the "order of things" in nature, which supposedly exist independently of the human subject, a "knowledge in the real". This Lacanian conception of modern science is crucial. It evokes his remarks on the subject of science from "Science and truth". He indicated there that modern science, which was born in the 17 th century, was the precondition for the discovery of the subject of psychoanalysis (Lacan, 1966:6-7). How are we to understand this? Knowledge which exists in nature presupposes a subject for whom this knowledge is meaningful. It also implies a subject who has a desire to know this knowledge. This subject is called the "subject of science" and it is the subject upon which psychoanalysis operates. Modern science made the decision to find certainty in the object and concentrated its efforts exclusively there. Freud discovered, underlying this search for certainty, a doubting subject and set himself the enormous task of studying the relationship between this subject and the object. In this task he stumbled upon the problem of meaning and language as the elements which connect the two, but which also obscure their relationship at the same time.

Towards the end of the 19th century Freud realized that language is an important part of the human psyche. He observed that the psyche is structured and that using language in certain ways can establish a change in people. Asking people to "freeassociate" he found the focus and emphasis of their speech to be forever shifting. One thing would always lead to another, never settling onto something specific. Freud had discovered displacement 
as one of the mechanisms of the psychic apparatus. But he had also discovered that this psychic apparatus was centred around a lack which people would avoid. Freud defined this lack as the object that is lost when we have to tear ourselves away from our place of origin; it represents an original satisfaction that is gone forever. It can be represented initially in hallucinations and only later in words. Freud had no conceptual tools at his disposal to ground these discoveries in a theory of language; a theory that could include the subject and this object. Not that this theory didn't exist in his life-time, he just did not know about it. ${ }^{1}$ These conceptions of the object, the subject and language have far reaching consequences for our understanding of science and the question of diagnosis in clinical work.

The relationship between the subject of science and his or her object of study is of an impotent nature, because every progressive step in scientific research leads to the further retreat of its object. For instance, advances in neuroscience and neuropsychopharmacology only seem to lead to the discoveries of ever more neurotransmitters and newer forms of interactions between them, whilst none of these discoveries take us any further in our understanding and treatment of psychopathology. ${ }^{2}$ But that is not all. The further the object of science retreats, the more the subject of science tends to step forward. This situation is absolutely antithetical to the ideal of scientific objectivity. A remark by John Hughes, Professor of Neuropharmacology at Cambridge University, might serve as an illustration of this point: ${ }^{3}$

You know you have to be convinced, you really have got to be convinced in science that you are right. This business about the impartial scientist assembling facts in order to disprove a hypothesis is absolute balderdash. Karl Popper could never have been further from the truth. You have got to be convinced. Yes, and I think most scientists are deluded. [Healy, 1996:545] ${ }^{4}$

We could conclude from this remark that, as a scientist, Hughes does not have much time for the painstaking and meticulous work of gathering data using the empirical method of objective scientific research, which according to Popper, should lead to progress in one's scientific work providing that this happens on the basis of continous falsification of hypotheses. The implications of Hughes' 
remark are that scientists can be convinced about the truth before research is done and that science only has to prove that they were right in their conviction. Objective science, in that case, is only a matter of what the subject of the scientist intuitively knows already.

The history of psychiatry in the 19th and 20th centuries is the history of the continuous attempt and failure to isolate the functional area of the psyche which would give a conceptual unity and clarity to the differential clinic of psychopathological disorders. ${ }^{5}$ This failure causes psychiatry to revert back to the relative security of nosological systems and classifications which are meant to grasp a clinical reality. The security provided by nosology and classification is the illusion of control and mastery over something which is unknown or not understood and it is indeed an illusion because nosological names never correspond to empirical reality; in fact they rather obscure that reality (Verhaeghe, 1994:62). The latest and perhaps best known of these classifications is the DSM system (I-IV), The Diagnostic and Statistical Manual of Mental Disorders. In relation to such diagnostic classification systems, Dany Nobus writes:

The categories of mental disorders included in the diagnostic manuals function as prototypical examples of states of psychic illness that can be determined through observation and deduction. Nevertheless, the univocal empirical recognition and delineation of mental disorders remains a psychiatric sign, since a perfect objectivity and a fully adequate categorical system are impossible to realize. Current diagnostic systems for mental disorders have many epistemological shortcomings, which are often acknowledged by psychiatrists themselves, but they continue to be used, in many cases because professionals are convinced that there is nothing better available. Of course the question is what this better thing would be: a more guaranteed objectivity through a system with more or less differentiations, or a radically different approach? [Nobus, 1997:53]

It is very important to look at the possibility of developing a radically different approach to our understanding of psychopathology and especially to addiction (as one of the manifestations of psychopathology) which, of all the mental pathologies, is arguably the one that occurs most frequently. This radically different approach is a necessity, because the attempt to find certainty in the object (of clinical reality), through naming and categorization, 
will only lead to a further retreat of this object and a further separation between subject and object. But there is the other danger of hoping that a similar epistemological shift will take place in psychiatry and psychopathology as took place in somatic medicine towards the end of the 18th century.

Positivist science, which depends on the observation, naming and classification of empirical reality, nevertheless assumes that in properly constituting itself as a science, it will make a similar transition as that which characterizes the emergence of modern clinical medicine. That means that it hopes to move from a classification of observations to the postulation of an underlying functional dynamic of which these observations are only the visible manifestations. What the history of psychopathology shows is an oscillation between elaborate classification systems, such as the DSM, and the attempt to isolate from this a differential clinic based on functional unities. Up to now, this attempt to establish a differential clinic based on functional unities has failed to sustain itself in the domain of psychopathology.

Paul Verhaeghe has divided approaches to psychopathology in the 18th and 19th century into two broad categories (Verhaeghe, 1994:74-97). I will outline some aspects of the two categories, because in some respects the ideas put forward in this important, but untranslated Dutch text, converge with the history we have just sketched and, more importantly, will lead to similar conclusions. Verhaeghe makes a distinction between what he calls the "wishful dream of positive-science" and the "moral treatment paradigm".

The first is the paradigm of reductionist materialism, and has roots that go back to Democritus who postulated that everything can be reduced to fundamental particles. The basic premise, propagated by Bayle, is that every psychopathology should have one specific organic cause (or be based on a disorder in one specific functional unity) and should therefore be organically treatable. The accidental discovery of neuraleptica in the early 1950 s gave new impetus to the idea of organic causation. The logic was as follows: if chemical substances can have an effect on pathological behaviour, then the cause of this behaviour must surely be chemically based as well. One of the consequences of this scientific way of thinking is that the subject is excluded. The illness is defined as a nosological essence and the patient is only its vehicle. In fact, even as a vehicle, the patient is 
an interference in the understanding of the nature of the disease. The subject is a passive victim of an organic agent and carries no responsibility whatsoever for his or her mental problem or disease.

The second paradigm, the moral paradigm, has roots in the fifth century before Christ when the sophist Protagoras postulated that all perceptions could be reduced to their subjective determination and can therefore only contain an individual truth (for instance, two people seeing the same thing does not mean that they experience it in the same way). Despite this position, Protagoras does accept that certain perceptions are better than others: the perceptions of healthy people are better than those of sick people. Better perceptions are those that have better factual consequences. This leads to a paradox involving the simultaneous claims that perceptions are always subjective, and that some perceptions have better "factual" (objective) consequences than others. The inevitable consequence of this paradox is that, despite the aspect of subjectivity, one depends on an authority, or a master who knows, for knowledge about the difference between good and bad perceptions. The relevant consequences of this concept were the special institutions created, such as psychiatric asylums and hospitals which were headed by a master or "chef de clinique" who would know what is good for the patient. Essentially, diagnosis and treatment within the moral paradigm come down to this: people become mentally ill as a result of sick-making perceptions or ideas, and treatment is done in a healthy environment with the help of a masterful figure. In other words, treatment takes place within a discourse in which there is no place for the choices, desires and responsibilities of the subject. This paradigm is strongly reflected in today's social/psychological approach.

It is striking that both paradigms rely on external factors. In the first paradigm the subject is the victim of an organic factor and in the second paradigm the environment is responsible for the problem of the subject. Consequently, this subject is an "accidental" component in the therapeutic mechanism and the treatment takes place despite his or her responsibility.

But psychopathology has not managed to reduce itself in any stable way to the functional systems of the brain and their disorders, nor has it managed to grasp clinical reality in a perfect and unequivocal language, reminiscent of the famous statement of the 18th century sensualist Condillac, who said: Une science parfaite serait 
une langue bien faite (A perfect science requires a clear language). It is as if psychopathology refuses to separate itself from subjectivity, language and culture. What the history of psychopathology shows, above all, is the constant attempt to exclude the subject and subjectivity (of both clinician and patient) from its full investigation. Psychopathology tries to find certainty in an unstable object of study and in the process it manages to ignore the relationship between subject and object and between subject (of the clinician) and patient.

In terms of a scientific conception of psychopathology and treatment of psychopathology, the aforementioned paradigmsincluding classificatory medicine and functional (or somatic) medicine-have in common the fact that the subject (of both patient and clinician) stands excluded in relation to the cause as well as in relation to the treatment. That surely must lead to an impasse, because is it not the subject who is happy or unhappy, who has pleasure or pain, who suffers or manages to avoid it, who will have to die and accept this or not, who will be confronted with the otherness of - and within - the Other sex, and, who ultimately is the only one who knows-whether he or she is consciously aware of it or not-the true nature of their relationship to these sensations, feelings, thoughts, experiences and responsibilities? Can we believe that these thoughts, experiences and their causes exist independently of us? Or can we be told precisely how to go through-or live with-these experiences by persons who are subject to these experiences themselves? What is interesting about these questions is that they defy both an objective and a moral answer. Instead, they demand an ethical response. For instance, to die cannot be positively known nor is it good or bad. All we know is that we will have to come to terms with the fact that death will come and that that fact is beyond good or bad. The ethical response is to allow subjects to reconcile themselves with this fact, irrespective of the successful outcome of this process, because success implies having reached an external objective or ideal.

\section{The Freudian Intervention}

Freud shifted emphasis from the eye to the ear in his clinical practice. The difference between seeing and listening is quite 
enormous. What you see is what you see, but when you listen you can hear things. Things that are hidden from the eye, things that have meaning or - when not understood - can cause distress. What Freud heard was that meaning is not always obvious, nor the language that produces it. Freud heard the existence of the unconscious. This discovery of the unconscious allowed him to generate a psychopathological clinic based on the dialectical interaction of subjectivity and clinical structure, thus undermining any attempt at strict differentiation and separation of subject and object in the psychoanalytic arena. This dialectical interaction transforms the classical psychiatric nosography and provides it with the possibility of a theoretical unity. This is however a form of unity that is not acceptable to the pretensions of objective and empirical science who prefer instead the unity of the observable object and the unity of word or concept and thing. The preference for this kind of unity in objective and empirical science, so prevalent also in the domain of psychiatry and psychopathology, has led to an impasse, especially in the area of clinical diagnosis. ${ }^{6}$ The failure to create a diagnostic system that classifies symptoms and syndromes of mental disorders on the basis of a precisely locatable causation, a uniform etiology and an accurate prognosis for each disorder, i.e., the failure to create a diagnostic system that matches up perfectly with clinical reality, has become blatantly obvious in clinical practice. Moving away from diagnosis and treatment, psychiatry, to a large extent, has become a practice of patient management and patient care. And where this transformation has not taken place (yet), psychiatry and clinical diagnosis are largely a practice of intuition based on personal experience. Verhaeghe writes:

Every clinician has experienced in his life a certain amount of anxiety, depression, relationship problems, problems in growing up, etc. As long as what he encounters in his client is situated within the limits of his own experience, he will consider this more than likely as "normal". However, if what he encounters in his client is situated outside his quantitative field of experiences, he will suddenly diagnose it as pathological and if it is situated outside his qualitative field of experiences, the diagnosis will become psychosis. [Verhaeghe, 1994:35]

There are simply no absolute criteria available that would neatly 
indicate the quantitative and qualitative differences between the different categories of mental illness and pathology. The reason for failing to develop these criteria-and criteria are ultimately nothing else than points of reference which determine the difference between normality and abnormality - is based on the fact that there is nothing outside language that can guarantee the absolute validity and truthfulness of these criteria. Therefore the unity between clinical category (or concept) and clinical reality (or object) cannot be established. There is no a priori correspondence linking the two orders. In psychoanalysis there is really only one point of reference, or one criterion for truth, and that is that the constitution of the subject in language entails the confrontation of the subject with the trauma of a lack. All subjects, in their own way, try to come to terms with that fact. Everything the subject does, whether in language or outside language, is to be understood as the attempt to live with this trauma of the lack.

Considering the impasse in clinical psychiatry and psychopathology in terms of failing to develop a coherent clinic of diagnosis and treatment (in psychiatry treatment is to a large extent dependent on making the correct diagnosis), it might be worthwhile to look at the possibility of applying the theoretical unity of psychoanalysis to the clinical area of addiction. In no other clinical area is it more obvious that the relationship between subject and object can be very problematic and extremely disturbed. For this reason it makes sense to apply a theory that is based on the relationship between the subject and object and to apply a psychopathology that centres around the different structures, modalities and avatars that characterize this relationship. For instance, the attempt to establish a differential diagnosis of perversion based on the description and classification of sexual behaviours, their consequences and the contexts in which they occur, ultimately failed precisely because it ignored the clinical structure of the relationship between the subject and the (sexual) object (Nobus, 1994:132, 142; Temmerman, 1994:126, 127; Verhaeghe, 1994:242, 243). Another reason why it makes sense to consider the possible contribution psychoanalysis can make to the area of addiction is that the contributions made by objective and empirical science or psychiatry have so far only led to unsatisfactory results that show an alarming inconsistency. A coherent diagnosis of addiction-based on the 
description of addictive/compulsive behaviours (drug taking, alcohol consumption), the addictive/toxic characteristics of drugs and alcohol (and their effects on the psyche, soma and social environment), and the course and development of the addictive disorder/disease-has not been succesfully realized. Nor has it been possible to establish a precise cause-and-effect relationship between addiction and specific psychological characteristics, social factors or medical/organic anomalies that can explain the phenomenon of addiction in a uniform way. ${ }^{7}$

It appears that something in relation to addiction is indeterminate. In other words, it is very difficult to positively define either addiction or drugs themselves (including alcohol). Perhaps the most commonsense definition of a drug is that it is a substance which when incorporated produces alterations of the mind and the body. This definition makes so much sense that it has no explanatory value. Coffee, tea, tobacco, sugar, water, food, prescription drugs, illegal drugs, can all be incorporated and may even act as drugs. A lot of people are addicted to alcohol, but can we say that it is a drug? Is it perhaps a poison, or a food? Particular drugs taken in certain doses can become poisons but in other doses function as remedies (Plato already hinted at this ambiguity of the pharmakon). Does a drug become a medicine when it is made available only by medical prescription (it seems that marijuana is now going to be used for the medical treatment of glaucoma, whilst amphetamines travelled the other direction by crossing over from being legal to being illegal) and what exactly is the difference between prozac and ecstacy besides the legal aspect? (Lenson, 1995:4). The history of legislation of drugs shows that, in terms of function and effects of drugs, the law is arbitrary. Despite these indeterminate and undefinable aspects of drugs and drug-taking we definitely know that addictions exist. The real problem is how to study them. Empirical science relies for its assertions on statistically significant data gathered from so-called representative samples. This approach is therefore never in a position to address the relationship between drug (object) and addict (subject). A consequence of the empirical method is the assumption that drugs cause uniform effects implying that the effects are only related to the drugs and indeed have nothing to do with the relationship between the object-drug and the subject-user of the drug. Empirical science is forced, by its 
methodology, to avoid considering the possibility that toxicity and the effect of drugs are inherent to the subject. This conception fails because drugs are profoundly ambiguous in both their function and their effect. They can function as poisons or as remedies. Concerning their effect, it is a well-known fact that drugs and alcohol can affect people differently and can affect the same person differently at different times. In other words neither function nor effect is uniform. ${ }^{8}$ Objective and empirical research fails in the area of addiction because the subject (yet again) throws a spanner in the works. Or perhaps it is better to say that the subject is not allowed to put in its spoke. Alain Delrieu, who published a very detailed study of more than 400 written texts on addiction published in the 19th and 20th century to which he gave the title L'Inconsistance de la Toxicomanie (The Inconsistency of Addiction), concluded: "Despite the multiplicity of scientific disciplines which are interested in this theme, it is actually impossible to respond in a straightforward way to two questions which obsess the adult world, 'why do so many young people take drugs?' and 'who are those who take drugs?'" (Delrieu, 1988:101, my translation). In other words, addiction exists, but there is no such person as the (typical) addict. This is precisely the point Markos Zafiropoulos refers to with his book title The Addict does not Exist. ${ }^{9}$ Despite the uniform social, legal and medical manifestation of addiction, the relationship between addiction and the subject is neither uniform nor predictable in any way. Listening to the discourse of addiction is perhaps a way out of the impasse. That means listening to the speaking subject who is addicted and that implies a listening beyond a general symptomatology. But what can we say about some of what has been heard so far?

Civilization and its toxicomanias-rudiments for a differential diagnosis of addiction based on the concept of "administration"

In the very last pages of Civilization and its Discontents Freud diagnoses the disorder in human civilization in a way that would not be acceptable to psychiatry. In his observation of civilization he has come to the conclusion that it is an irrefutable fact that man wants happiness, but cannot have it. (Freud, 1930:145). In other words, man is destined to suffer. Earlier on in the article he wrote: 
But the most interesting methods of averting suffering are those which seek to influence our own organism. In the last analysis, all suffering is nothing else than sensation; it only exists in so far as we feel it, and we only feel it in consequence of certain ways in which our organism is regulated. The crudest, but also the most effective among these methods of influence is the chemical one-intoxication. [Freud, 1930:78]

The connection, established by Freud here, between suffering, the regulation of our bodies and intoxication is extremely interesting and demands further exploration. The immediate context from which this quote is taken is crucial for an understanding of the problem of addiction in the field of psychoanalysis. I will therefore explore this context in some detail here. Freud indicates that suffering threatens us from three directions: our bodies, the external world and our relations to others (Freud, 1930:77). This last source causes us most suffering. Isolating ourselves from others is thus one solution to our problems. Drugs and alcohol can provide us with pleasure, but they can also render us incapable of "receiving unpleasurable impulses". These two effects appear to be intimately connected with each other. Both the pleasure these "foreign substances" can generate and the halt they can call to unpleasurable impulses, whether they come from within or outside the organism, are independent of the Other. Freud writes: "The service rendered by intoxicating media in the struggle for happiness and in keeping misery at a distance is so highly prized as a benefit that individuals and peoples alike have given them an established place in the economies of their libido" (Freud, 1930:78). Implied in this statement and its wider context we already encounter the rudiments for a possible differential diagnosis of addiction which is not based on observation of empirical material, but is based on a certain economy and distribution of pleasure and jouissance. The economy and distribution of jouissance result from the constitution of the subject in language (or the field of the Other). In an article entitled "Libido and toxic substance", I have argued how the constitution of the subject in language is able to represent "certain ways in which our organism is regulated", how different forms of jouissance result from this process, and how certain distributions of these forms can lead to toxicity and indeed cause suffering, pain and anxiety (Loose, 1996:32-43). I will briefly outline that argument here. 
In the latter part of his work Lacan became very interested in the body. In Seminar XX, he says that we enter reality with the apparatuses of jouissance and that there is no other apparatus than language (Lacan, 1998:55). Language is therefore a form of jouissance, a kind of enjoyment that is different from the jouissance of immediate experience and total vitality. The introduction of the signifier causes a differentiation of jouissance. But it causes more than that! It produces a subject, it allows this subject to speak and it turns the being of a real organism into a body which it can have. Freud's point of departure was that the constitution of the human subject is not a very successful process and Lacan made the point that this failure also applies to the body. Language, or the signifier, is structurally incomplete and because of that fact it constitutes an only partially symbolized body in language. These real (unsymbolized) parts of the body can become cause for suffering and in that sense they have a toxic effect. ${ }^{10}$ The use of drugs and alcohol can serve as an attempt to regulate this toxicity of the body. It is important to note that the real toxicity is not situated in the alcohol or drugs but in the body. ${ }^{11}$ The signifier also creates a lack in the subject by cutting him off from a primordial jouissance which characterizes the dual unity with the mother/universe (Freud's oceanic feeling). This is known as symbolic castration. Symbolic castration leaves the subject unsatisfied because it will desire something more than ordinary pleasure or jouissance. Yet when this desire threatens to be realized, the subject will panic as this heralds his annihilation. The realm beyond ordinary pleasure is the realm of the death-drive. Drugs and alcohol can function as attempts to break with ordinary (thus limited) pleasure (or phallic jouissance) and produce something more or indeed, occasionally, they can function as barriers against the lethal or toxic domain beyond ordinary pleasure which threatens to annihilate the subject. In the latter case, the toxicity is not situated in the chemicals, but in the subject. On top of this the introduction of the signifier leads to a speech which never reaches its full potential. ${ }^{12}$ For all these reasons it is inevitable that the subject not only desires bigger and better things, but will also suffer and experience anxiety. This brief outline shows that in a Lacanian conception of the subject, drugs and alcohol can function differently for different people, in terms of their relationship to jouissance, pleasure, anxiety, pain and their body. It is 
undoubtedly the case that this has consequences for treatment, as the effect of alcohol and drugs will be (at least to some degree) determined by the way they function for the subject.

Another important aspect of addiction, which Freud makes quite explicit in Civilization and its Discontents, is his insistence on the fact that addiction is a social symptom. He writes:

We owe to such media not merely the immediate yield of pleasure, but also a greatly desired degree of independence from the external world. For one knows that, with the help of this "drowner of cares" one can at any time withdraw from the pressures of reality and find refuge in a world of one's own with better conditions of sensibility. As is well known, it is precisely this property of intoxicants which also determines their danger and their injuriousness. [Freud, 1930:78]

Addiction as a social symptom creates a specific social bond and forms a particular structure. All three clinical structures of the subject in psychoanalysis form social bonds and are relational in nature; they orient the subject in relation to the Other. These three positions in language represent three different ways in which subjects can manage with - or orientate themselves to - the original structural trauma or lack. If it is permissible to define the clinical structures (and addiction) with only a few words based not on the results of psychological measurement, but on a structural conception of the relationship between the subject and Other, then we can say the following:

- Neurosis addresses the Other with a question. That means that the subject has unconsciously accepted symbolic castration and its consequence; it takes responsibility for the lack, it renounces primordial real jouissance, puts up with ordinary pleasure and with the inevitable guilt and anxiety.

- Perversion dresses the Other with an object. That means that the subject sometimes acknowledges the lack and at other times refuses this. The mother is not lacking and in order to disavow this fact (and ultimately symbolic castration), the subject replaces the lack with an object. Primordial real jouissance is given up, but a particular jouissance related to a specific object comes in its place. Anxiety and guilt are often hidden and therefore less obvious in this structure. 
- Psychosis is being or not being the Other. That means that there is no relationship to the Other for the subject. Language has been foreclosed; symbolic castration and the lack have not been accepted. Primordial jouissance is not given up and the subject is either overwhelmed by it, or else protected from it, by delusions and hallucinations. Anxiety and guilt are all or nothing in this structure.

- Addiction is an independence of the Other. That means that the relationship between the subject and the Other is one thing, the addiction is something else (and somewhere else). Symbolic castration and lack can be accepted, disavowed or rejected by the subject; addiction seeks administration. Anxiety and guilt are hidden at times, but paradoxically maintain an "obvious" (hidden) presence.

Administration refers to an important concept whose theoretical value and clinical application are not immediately obvious. If neurosis is based on the mechanism of repression, perversion on disavowal and psychosis on foreclosure, then I propose to base addiction on the mechanism of administration, on condition that it is considered to function at a different level than the other mechanisms. Administration is not a mechanism that functions at the level of the subject; it functions at the level of the (social) symptom. But that does not imply that it exists without a relationship to the subject. The mechanism of administration does not designate the way the subject is constituted in the field of the Other. It designates the way the symptom functions in relation to the Other and it is this function that is dependent on the position of the subject (vis-aे-vis the Other). When I propose that addiction maintains an independence of the Other, I imply that it is an attempt to administer a jouissance independently of the Other. Jouissance here refers to both ordinary pleasure that makes life coherent (Freud's pleasure from the pleasure principle) and to pleasure that is not curtailed by the normal limitations of human culture or social life and subverts coherent life (Freud's beyond of the pleasure principle). The dynamic tension between these two human tendencies is the cause of the failure of the pleasure principle and is fundamental to human nature. It was already an object of serious contemplation for the Stoics and Epicurians (the two opposing schools of ethical thought 
in ancient Greece) and it lies at the heart of (the human problem of) addiction. The term administration is used in three ways: (1) to govern or regulate; (2) to manage as a substitute; and (3) to dispense or supply.

Addiction can be related to the three clinical structures of psychosis, neurosis and perversion. But it can also be related to Freud's (often forgotten) clinical category of the actual neuroses, and that would make addiction a clinical entity which is separate from the clinical structures and their symptoms. This clinical category of the actual neuroses can also play an important role in the development of a differential diagnosis of addiction. ${ }^{13}$ The chemical processing of actual neurosis is a fourth form of addiction and it is a form of addiction that has its own relationship modality vis-à-vis the Other. This relationship modality is characterized by the independent adminstration of jouissance which functions as the governing or regulation of an unbearable real; a real that threatens to annihilate the subject in actual neurosis. ${ }^{14}$

In psychosis, the foreclosure of language (or the rejection of symbolic castration) results in a position of the subject as an object or "Thing" for or in the Other. The lack, which is produced by the constitution of the subject in language, is not produced for the psychotic subject, precisely because he or she is foreclosed from language. This psychotic subject will be confronted with a massive presence of the real; an unbearable "too much" of something. The defensive reaction of the subject against this massive immediate presence of real jouissance, can take the form of a "suppletion symptom" or what Lacan calls a "sinthôme" in Seminar XXIII (Lacan, 1977:lecture of 18-11-1975). The other solution available to the psychotic subject is to develop a delusion against the massiveness of the real. A delusion is constructed on the basis of language; it is a signifying system. But language functions differently for the psychotic subject than for the neurotic (or perverse ) subject. For the latter, language contains a structural lack which makes the signifiers continually shift as the subject tries to find certainty about a truth that always seems to escape. For the psychotic, language (which is the material for the delusional system) has to be complete in order to form a defense against the real. Language functions as a protective wall which is meant to be impenetrable. That is why psychotics "know for sure". It is a 
protection that must provide absolute certainty for psychotics, but it is also something that can make them paranoid as there is no doubt about the fact (only neurotics doubt) that it can always be taken away by this Other. These forms of psychosis are delusional (megalomania) or paranoid. When there is no "sinthôme", paranoia or delusional system available, the psychotic subject and his or her body will be completely at the mercy of the real; they will be overwhelmed or invaded by jouissance. This is the schizophrenic (catatonic) form of psychosis. Here we find the connection between psychosis and addiction. In the event of the signifier being unable to function as a protection against the invasion of jouissance, the subject always has recourse to the route of the body via drugs and alcohol. Addiction here is a form of management (of jouissance) by substitution with drugs and alcohol as forms of self medication. Also here we encounter some of the chronic addictions.

In neurosis and perversion the mechanisms of repression and disavowal result in a fundamental dissatisfaction due to a failure of the pleasure principle. What lies beyond this pleasure principle is always "too much" and yet the absence of this beyond creates a "never enough", a plus-de-jouir (more-to-be-enjoyed). Here we can situate one of the few (maybe the only) reference(s) Lacan makes to addiction: "everything which permits the escape from this marriage (to the phallus) is clearly very welcome, that is the reason for the success of drugs, for instance; there is no other definition for drugs than this one: it is what permits to break the marriage to the little Willie" (Lacan, 1976:263-270, my translation). Lacan indicates here that addiction is an attempt to break away from phallic jouissance and an attempt to turn the pleasure principle into a successful operation through the refusal of symbolic castration. It takes the form of the subject dispensing with the failure of the pleasure principle by supplying himself with an additional jouissance. The drug or alcohol here functions as an "object-cause-of-jouissance" which allows the subject to avoid the always problematic encounter with the desire of the Other and sustains in him the illusion that he is able to attain the lost "object-cause-of-desire." This implies direct access to jouissance for the subject, enabling him to avoid the long detour via the Other because it can be administered at will. It is therefore essentially oral in nature and drowns the symbolically structured "formations of the unconscious" in a sea of toxicity. 
Despite the attempt of neurotic (and perverse) addicts to break away from phallic jouissance in an act that takes place independently of the Other, it is undoubtedly the case that this act is, at the same time, an appeal to the Other as it was the encounter between the subject and the Other that produced the dissatisfaction of having to put up with limited pleasure and desire. In other words, the act of neurotic and perverse addicts is an appeal to the Other in the form of a complaint. The discourse or speech of addicts is full of complaints. A complaint is a question, a demand directed at an Other. It is a demand to be relieved of suffering; a demand for help, a demand for a solution to the problem of desire. The complaint as an expression of pain and suffering also contains an accusation or an attribution of the cause of this pain and suffering to an external source. This external source is the Other. The human dilemma is that the Other is indeed the cause of the subject's suffering, but the subject will always have to take responsibility for dealing and living with this fact. Addiction, based on neurotic or perverse structures, attempts to avoid this problematic and fundamental human dilemma, by repeating this dilemma at a different level and in a way which is utterly destructive. On the one hand addiction functions independently of the Other for the subject, whilst on the other hand the subject is dependent on the act of repetitive drug taking. In terms of treatment, this act should be interpreted as an appeal for help and as an analysable symptom. The problem is that the independent function (vis-à-vis the Other) of addiction creates complications for the transference. Addicted subjects will tend to escape the encounter with the desire of the Other (which the therapeutic or analytic relationship provokes), by taking drugs or alcohol in order to avoid the anxieties and uncertainties that are inherent to the therapeutic process.

It is without doubt the case that these different forms of addiction have implications for the direction of treatment. That is the reason why a diagnosis of addiction which includes the subject is of crucial importance for intervention in the field of addiction. It is essential to know what we are dealing with and to that effect we need theory to guide a clinic that includes addiction. This is a clinic which allows the subject to find or create a different orientation towards jouissance and the real via the object and signifier of the transference. The only problem is that the real of psychoanalysis 
(the real on which it operates) is not the only real. It is not the real of modern science.

\title{
Conclusion: toxico-mania in modern culture and medicine
}

In their book Intellectual Impostures, Sokal and Bricmont accuse Lacan and his disciples of being theoretical and this at the expense of observations and experiments (Sokal \& Bricmont, 1998:34). They insist on the absolute necessity of empirical evidence in order to be able to say something scientific about the natural and human world: "Throughout this book, we have defended the idea that there is such a thing as evidence and that facts matter" (p. 197). Let us look at some of the facts of human existence and nature that can be easily observed. At times people are at war and kill each other. There is no doubt about that and this is a fact that didn't escape Freud. Towards the very end of Civilization and its Discontents he writes:

\begin{abstract}
Men have gained control over the forces of nature to such an extent that with their help they would have no difficulty in exterminating one another to the last man. They know this, and hence comes a large part of their current unrest, their unhappiness and their mood of anxiety. [Freud, 1930:145]
\end{abstract}

We stated before that man wants to be happy but cannot be happy. This is a fact observed by Freud and something for which he had obviously ample evidence. But his explanation of this irrefutable fact is theoretical. The reason why Freud wants to explain this fact theoretically is that the existence of evidence is not sufficient to explain this fact. Freud's point of departure is that there is an irreducible real element in human nature or existence that causes pain and suffering. This real element is not the kind of real that is at stake in science. This real escapes the methodology of human science (statistics do not help here in order to explain the evidence by giving the observed data some validity), but it also differs from the real of modern science (in the form, for example, of technological products). The real in science is either related to a general kind of knowledge or else it is something that is produced as an object in the real. But neither scientific real can be equated to the real of the human subject which causes symptoms and discontent in 
civilization. Lacan says: "It is clear that the knowledge imputed to something in the real, whether one calls that God or something else, has in no way anything to do with the knowledge which articulates itself especially from this, that there is a being who speaks" (Lacan, 1998:21, my translation). Knowledge imputed to the real in science is not the knowledge related to the real of the unconscious of the subject. The real of the unconscious has a relationship to meaning, because it wants to find an expression of an inexpressible jouissance. This distinction between the real of science and the real of psychoanalysis is essential and-paraphrasing Eric Laurent-it is extremely important to convince science of the fact that there is another form of real than the one of science (Laurent, 1998:42). This is the fact that man has to be torn from his place of origin which causes a differentiation in-and problematic distribution of-jouissance in the subject. Civilization is an attempt to regulate this distribution; it is in that sense "a mode of jouissance, and even a common mode of jouissance, a systematical distribution of the ways and means to jouir" (Miller, 1998:25). There is no doubt about the fact that the products and gadgets of modern science are very effective ways of producing, regulating and distributing jouissance.

Freud's theoretical explanation for man's incapacity to be happy is that man is caught between an egoistic urge for happiness and a cultural urge for unity in human kind. Man is unhappy because the latter urge has pushed the former into the background (Freud, 1930:142,143). These two opposing urges represent the individual and cultural super-ego (pp. 141,142). Freud's diagnosis that mankind has become neurotic was based (as we stated in the introduction to this chapter) on the influence of the cultural urges. In other words, man's neurosis and lack of happiness are based on the dominance of the cultural super-ego over the individual super-ego. Freud's cultural super-ego is one that forbids, restricts, sets ideals, provides rules and so on. It causes unhappiness because the demands of the cultural Other force the subject to renounce its claim for individual happiness.

This does not seem to tally with today's preoccupation with happiness, enjoyment, (extreme) pleasure, individual lifestyles and success. J.-A. Miller writes: 
existence of the Other-in so far as it rivets the subject to the pursuit of surplus-jouissance. The Freudian super-ego produced things like prohibition, duty and indeed guilt-so many terms which make the Other exist. These are the semblents of the Other. They suppose the Other. [Miller, 1998:26]

Has the cultural super-ego (which Freud diagnosed as being the cause of our unhappiness) been replaced by another super-ego, one perhaps that puts more emphasis (or even pressure) on the individual super-ego thereby demanding more happiness in the process? This would be a super-ego closer to the spirit of our civilization. Miller argues that the Lacanian super-ego with its imperative to enjoy is the super-ego of our times. (Miller, 1998:26). If a change of super-ego has taken place, this change should also be reflected in the development of modern science. Subjects in modern times are more subjected than ever to gadgets and non-linguistic apparatus of enjoyment. An increasingly significant aspect of modern science has to do with the accumulation, control and distribution of material objects. These objects are objects in the real. Lacan says that we have access to an aspect of the real via gadgets and that we attribute these gadgets to the real because we do not construct them without the enormous scientific apparatus which in itself has nothing to do with these gadgets. (Lacan, 1998b:12). Once initiated by the subject, science can produce objects in the real in an automatic and sometimes accidental fashion, that is to say, in a way that is detached from the desire of the subject. This has an important consequence that was remarked on by Marc Strauss when he claimed that the foreclosure of the subject in science leads to the object running its own course, outside signification of desire, but not without jouissance value (Strauss, 1994:29).

In the 1950s such objects of jouissance value were produced more or less accidentally. These are the psychopharmaca and they are a scientific means to jouissance and the regulation of jouissance. The psychopharmaca are extremely effective and in that sense the use of psychopharmaca supports the subject in terms of his complaint about the Other which allows him to avoid exploring his own unconscious choices and responsiblities. They are a promise of happiness by the Other of civilization. The subject is not only ready to believe in the fulfilment of the promise of happiness, but in fact 
feels that science owes him this happiness. The psychopharmacologist Peter Waldmeier put it as follows:

So death or illness had another value for people a hundred years or more back from now and they accepted illness and they accepted death. Whereas when the treatments became available, some hopes were raised and people expected more and more from medicine and drugs. So in one way or another, people expected that whatever happens to them someone can help them and they can be terribly disappointed if they learn that in some cases this is not possible. I think this is something new. The roots are probably in the availability of treatments and the raising of hope. [Healy, 1996:578-579]

The distinction between the real of science and the real of psychoanalysis does not imply that one is without consequences for the other; it does not imply that there is no relationship between these two forms of real. The scientific production of objects of jouissance in the real can have a real effect on people. They can become overwhelmed by this jouissance and they might have to create different ways of responding to it. Esthela Solano made a very interesting remark in relation to this. She said that medical intervention is an intervention which forces the real of the symptom to respond differently and when one forces the real of the symptom to respond differently, that is never without consequences (Solano, 1998:51-52). In order to illustrate this point I would like to conclude with two more quotes from David Healy's book of interviews with famous and outstanding psychopharmacologists. These quotes sum up concisely the arguments I have put forward in this chapter.

Pichot: Panic disorder was created in its present sense by Donald Klein on the basis of differential responses to drug therapy. He has written down in detail how he came to the idea that there were two distinct disorders in the anxiety neuroses, one of them, the acute episode he named panic, reacting to the antidepressant therapy, while the other component, basic permanent anxiety, did not. It is true that the importance of a new disorder was later increased by world-wide trials of drugs, the result of which tended to influence key people. At the beginning, many French psychiatrists considered it as an uncommon disorder. But of course one finds a condition if one searches for it. [Healy, 1996:12] 
Ban: I had been engaged in research in which we induced psychopathology with drugs, and later on in research in which we controlled psychopathology with drugs; and since it was possible to do it both ways, I felt that finally we could meaningfully talk about mental illness because what we were talking about was no longer just a matter of belief, but was accessible and demonstrable experimentally. [p. 591]

So how do we respond to the neurosis of our times? By giving voice, not fuel (psychopharmaca), to jouissance. If our "enjoymentdemanding" cultural super-ego has forced the real of our symptoms to respond differently, perhaps we can conclude that some of the symptoms of the neurosis of our times tend to move in the direction of addiction and toxicomania. That makes the ethical response of giving voice to jouissance even more pertinent today.

\section{Notes}

1. In 1916 Saussure's Course in General Linguistics was published. In this book he makes a distinction in language between a layer of signifiers and a layer of signifieds. Neither layer is static, and they flow in no particular direction. The implication is simple: the relationship between signifiers and signifieds, or words and their meaning, is arbitrary. No word or concept refers naturally to a particular object or meaning. Arbitrary means that the relationships between signifiers and signifieds have been agreed by convention. Saussure also said that what characterizes signifiers is their difference from one another and a meaning can only be generated contextually, that is, through the context of other signifiers on the basis of this difference. Language is a moving material and it is set in motion by a lack that is inherent in the functioning of language itself, i.e., the lack of ultimate meaning.

2. Pierre Pichot, a professor in psychiatry, founder member of the Association for European Psychiatry and a renowned researcher in psychopharmacology, said the following in an interview: "The work done by neuroscientists is extremely impressive. I don't dispute that, but until now very little comes out of it in psychiatry in terms of concrete clinical applications" (Healy, 1996:17).

3. Although we must acknowledge immediately that his intentions with this remark might have been entirely different from our intentions here.

4. Hughes also says that he recognizes that "there are those out there that 
do pose the questions and go about it in a logical way." However, he does not consider himself to be one of those. He knows that delusions are dangerous, but a good scientist should be able to recognize that (Healy, 1996:545).

5. See Foucault (1973) passim.

6. The preference for this kind of unity in psychiatry (and psychopharmacology) was expressed very well by Tom Ban, Professor of Psychiatry at Vanderbilt University, when he said: "The only reason to have concepts is to be able to communicate, and if we have problems using a concept in communicating, we might just as well throw out such a concept. And if the dismissed concept leaves a void one should replace it with one which corresponds more with the real world (Healy, 1996:595).

7. As an illustration of the failure to establish a coherent diagnosis and a uniform explanation for addiction the reader is referred to an excellent and detailed summary of the psychiatric classifications of addiction by Mary McMurran (1994:19-21).

8. Freud was already aware of this lack of uniformity with the drug cocaine in 1887. In "Craving for and fear of cocaine" he connects the irregularity of the cocaine effect to individual variations (Byck, 1974: 175).

9. The original title in French is: Le Toxicomane n'existe pas (Zafiropoulos, 1988:1-106).

10. In Seminar XX, Lacan calls the jouissance related to this real aspect of the body, the jouissance of the body or the jouissance of the Other (Lacan, 1998a:4). He calls ordinary (sexual) pleasure or jouissance: phallic jouissance (bid. 8).

11. A psychoanalytic conception of toxicity does not necessarily consider toxicity to be inherent to drugs or alcohol, but can indicate anything that is detrimental to the subject. Toxicity, in this view, is therefore an inevitable aspect of human existence. It is nevertheless something from which the subject has to distance himself as much as possible. Toxicity in psychoanalysis includes the real (of the body), the realm of the deathdrive beyond the pleasure-principle, but also, for instance, suggestive words spoken in a hypnotic relationship. See also in this respect Sylvie Le Poulichet's excellent book Toxicomanies et Psychanalyse (1987:7-171).

12. This full potential is the ideal of communication which is the ability to say it all so that nothing needs to be said anymore.

13. From 1892 onwards Freud begins to develop a structural psychopathology. On the one hand he establishes the psychoneuroses (initially he called these the neuropsychoses of defence) and on the other hand he develops the category of the actual neuroses. The actual neuroses are characterized by an anxiety against which the subject cannot defend 
himself. The psychoneuroses display a whole array of (hysterical and obsessional) symptoms, all of which appear to form a relatively successful defence system against anxiety. This defence is indeed relative because psychoneurotics of course also experience anxiety. In fact, to be anxious is even their hallmark. There is however a difference in quality: psychoneurotic anxiety is more curtailed and less overwhelming. Psychoneurotic anxiety is contained on the basis of a psychic or symbolic processing of an original trauma that causes this anxiety. The cause of anxiety is the same for the actual neuroses, but the difference is that a symbolization or psychic processing of the original trauma never took place. Actual neurosis is the failure of a psychoneurotic development in the subject. The actual neuroses are an anxiety reaction to the direct confrontation with the real, because psychic processing is lacking in essential points. The psychoneuroses are a continous processing of this traumatic real with signifiers and symptoms (i.e., symbolically structured formations of the unconscious). The psychoneuroses are an attempt to cure the original real trauma. The actual neuroses lack this type of cure because there is no pacifying symptom. One way out of the actual neurotic impasse is by regulating the organism with drugs and alcohol. This solution of the toxic route via the body, which manages to avoid the encounter with the Other, is foolproof. Any solution that is able to avoid the detour of language is guaranteed fool-proof. The problem is that the subject will have to pay a heavy price. In order to maintain the solution the price will be addiction, because it is a solution without the possibility of a resolution: chemical intoxication is not a symptom that can be analysed and can therefore not be resolved. Some chronic addictions have their roots in actual neurosis. Addiction can be found in all three clinical structures and therefore addiction will acquire a function in relation to the Other in each of these structures.

14. The real toxicity in addiction, when considered as a separate clinical entity (by being related to actual neurosis), is not situated in the drug or alcohol itself, but concerns that jouissance of the body which threatens to devour the subject when the phallic or sexual jouissance of the signifier is unable to contain it. In "Libido and toxic substance" I argue that, in this case, addiction takes the form of a kind of "floodgate" which governs or regulates, in a homeostatic movement, the lethal attraction to the jouissance of the Other (Loose, 1996:40-42). Addiction, as a floodgate mechanism, replaces the function of the signifier here and forms a barrier against an anxiety which results from this other toxic jouissance, which overwhelms the subject when something of the body cannot be psychically processed or symbolized. This form of anxiety belongs to 
actual neurosis. Addiction as a separate clinical entity is not a matter of "not-having-enough", but a matter of trying to get rid of a "too-much"

\section{Bibliography}

Byck, R. (Ed.) (1974). Cocaine Papers. New York: Stonehill.

Delrieu, A. (1988). L'Inconsistance de la Toxicomanie. Paris: Navarin, Analytica nr 53.

De Saussure, F. (1966). Course in General Linguistics, C. Bally \& A. Secgehaye (Eds.). New York: McGraw-Hill.

Foucault, M. (1973). The Birth of the Clinic, A. Sheridan (Trans.). London:

Tavistock Publications.

Freud, S. (1887). Craving for and fear of cocaine. In: R. Byck (Ed.), Cocaine Papers. New York: Stonehill.

Freud, S. (1930). Civilization and its Discontents, S.E., 21. London: The Hogarth Press.

Healy, D. (1996). The Psychopharmacologists. London: Chapman \& Hall. Lacan, J. (1966). I a science et la verite. In: Écrits. Paris: Editions du Seuil. Lacan, J. (1976[1975]). Discours pendant la seance de cloture. Lettres de L'École Freudienne, 18: 263-270.

Lacan, J. (1977). Le Seminaire "Le Sinthôme", 1975-1976, J.-A. Miller (Ed.), Ornicar?, 9.

Lacan, J. (1998a). Encore the Seminar of Jacques Lacan-Book XX: On Feminine Sexuality, the Limits of Love and Knowledge, 1972-1973, J.-A.

Miller (Ed.), B. Fink (Trans.). New York: Norton.

Lacan, J. (1998b). Le phénomène Lacanien. Les Cahiers Cliniques de Nices, 1: 9-25.

Laurent, E. (1998). L'Attribution réelle du corps, entre science et psychanalyse, table ronde à Laussanne. Mental, 5: 41-58.

Lenson, D. (1995). On Drugs. Minneapolis: University of Minnesota Press.

Le Poulichet, S. (1987). Toxicomanies et Psychanalyse. Paris: Presses Universitaires de France.

Loose, R. (1996). Libido and toxic substance. The Letter, 6.

McMurran, M. (1994). The Psychology of Addiction. London: Taylor \& Francis.

Miller, J.-A. (1998). La passe de la psychanalyse vers la science: le desire de savoir. Quarto, 56.

Miller, J.-A., \& Laurent, E. (1998). The Other who does not exist and his 
ethical committees. In: M. Julien et al. (Trans.), Almanac of Psychoanalysis, 1.

Nobus, D. (1994). De kreten van de ademloosheid: artikulaties van het perverse fantasma. Psychoanalytische Perspektieven, 24: 129-143.

Vobus, D. (1997). Psychoanalysis and clinical diagnostics. JCFAR, $8 \& 9$. Sheridan, A. (1980). Foucault: The Will to Truth. London: Tavistock Publications.

Sokal, A., \& Bricmont, J. (1998). Intellectual Impostures. London: Profile Books.

Solano, E. (1998). L'attribution reelle du corps, entre science et psychanalyse, table ronde a Laussanne. Mental, 5.

Strauss, M. (1994). Psychanalyse et science. Quarto, 56.

Temmerman, K. (1994). Auto-erotische asfyxie: een "Status Quaestionis" van theorie en onderzoek. Psychoanalytische Perspektieven, 24. Verehaeghe, P. (1994). Klinische Psychodiagnostiek vanuit Lacans Discourstheorie: Impasses on Antwoorden. Gent: Idesca.

Zafiropoulos, M. (1988). Le Toxicomane n'existe pas. Paris: Navarin, Analytica nr 45. 